\title{
Using Acoustic Emission to Quantify Freeze-Thaw Damage of Mortar Saturated with $\mathrm{NaCl}$ Solutions
}

\author{
Ye Qian \\ Department of Civil Engineering and Engineering Mechanics, Columbia University \\ Division of Engineering and Policy for Sustainable Environment, Hokkaido University \\ Yaghoob Farnam and Jason Weiss \\ Lyles School of Civil Engineering, Purdue University
}

\begin{abstract}
Mortar samples were saturated with $\mathrm{NaCl}$ solutions of various concentrations and subjected to freezethaw cycles. Passive and active acoustic emission (AE) testing was conducted. The freezing temperature of the $\mathrm{NaCl}$ solutions in mortar corresponded with the sudden observation of passive AE events. The acoustic energy and damage parameter were calculated to evaluate the extent of freeze-thaw damage. The influence of the $\mathrm{NaCl}$ solution concentration and whether the solution freezes on freeze-thaw damage are discussed.
\end{abstract}

\section{INTRODUCTION}

The freeze-thaw damage of concrete materials has been studied for several decades. When water undergoes the phase transformation from liquid to solid (ice) the volume increases by $\sim 9 \%$. Powers (1945) described that the volume expansion forced the unfrozen water out of the pores when ice formed. The ice expansion and movement of water resulted in hydraulic pressure that lead to damage to the concrete. Later, Powers and Helmuth (1953) strengthened the hydraulic pressure theory through observing the sudden expansion (dilation) of nonair-entrained paste at the moment of freezing. The continuous expansion as the temperature was held constant suggested the unfrozen water flowing toward the freezing sites. It is also known that the formation of ice increases the concentration of pore solution, thus causing osmotic pressure. Scherer (1999) and Scherer and Valenza (2005) reasoned that the crystallization pressure between the ice crystal and the pore wall was the primary cause of freeze-thaw damage. The repulsion force is generated because the van der Waals forces between the ice and concrete pore wall are repulsive. No matter what the primary mechanism for freeze-thaw damage it can be stated that ice formation required for all the three forces: hydraulic pressure, osmotic pressure, and crystallization pressure.

Fagerlund (1973a, 1973b, 1975, 1977a, 1977b, 1981) proposed a theory of critical degree of saturation. According to this theory, when the actual degree of saturation exceeds the critical value, freeze-thaw damage occurs. It has been largely used to explain and predict freeze-thaw damage. Fagerlund (1973a, 1973b) mentioned that "at subfreezing temperature" the previous statement was reasonable. This work has been extended by Bentz et al. (2001) in the CONCLIFE program providing sorptivity-based service life prediction and in a series of experiments on plain and air entrained concrete (Li et al., 2011). Although this has frequently assumed water as the freezing fluid, the concentration of the solution could influence the freezing temperature and freeze-thaw damage.

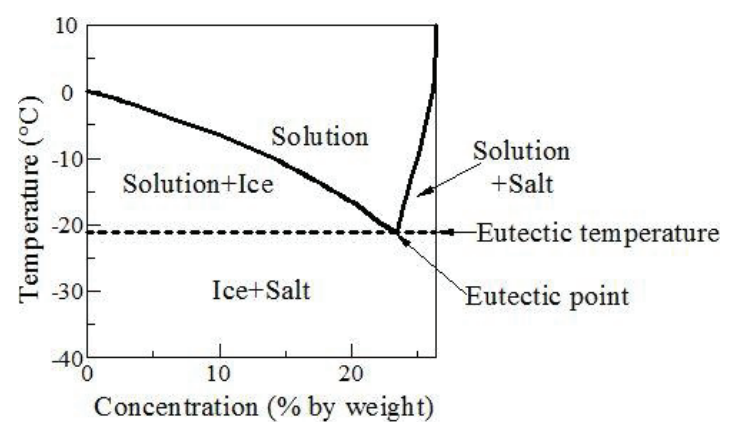

Figure 1. Phase diagram of $\mathrm{NaCl}$ solution (Grant, 2000; Ketcham et al., 1995).

Figure 1 shows the phase diagram of $\mathrm{NaCl}$ solution (Grant, 2000; Ketcham et al., 1995). The solid curve is referred to as the liquidus line which describes when ice begins to form in the $\mathrm{NaCl}$ solution. It should be noted that the freezing temperature in cementitious samples would be lower than the bulk 
solution because the solution is in confined pores (Fagerlund, 1973a, 1973b; Helmuth, 1960). For $\mathrm{NaCl}$ solution of concentration from 0 to $23.3 \%$ by weight, with increasing concentration, the bulk freezing temperature decreases.

In this study, various concentrations of $\mathrm{NaCl}$ solutions were used to saturate the mortar samples. Meanwhile, the freeze-thaw damage of mortar samples were recorded using passive and active acoustic emission $(A E)$ techniques. The freezing temperature of $\mathrm{NaCl}$ solutions in mortar samples was also recorded. The freeze-thaw damage was related to the concentration of $\mathrm{NaCl}$ solution and whether the solution in mortar froze.

\section{ACOUSTIC EMISSION}

Acoustic emission is a non-destructive testing method to detect and assess damage by capturing energy release and signals during cracking. These cracking could be caused by restrained shrinkage, mechanical loading, freeze-thaw cycles, and others. (Hossain et al., 2003; Kim \& Weiss, 2003; Malhotra \& Carino, 2004) when cracks initiate and propagate. The stress wave generated by cracking can be captured and used to quantify damage. Figure 2 shows a typical waveform of a stress wave. The amplitude of waveform is the maximum absolute value. To avoid detecting surrounding noises, a threshold amplitude value is assigned. An acoustic event starts when the amplitude of the waveform first exceeds the threshold value, and ends when the amplitude decreases below the threshold value for the last time. The acoustic energy is the absolute value of the integral of the voltage versus time. The number of acoustic events and cumulative acoustic energy could be used to evaluate the extent of damage.

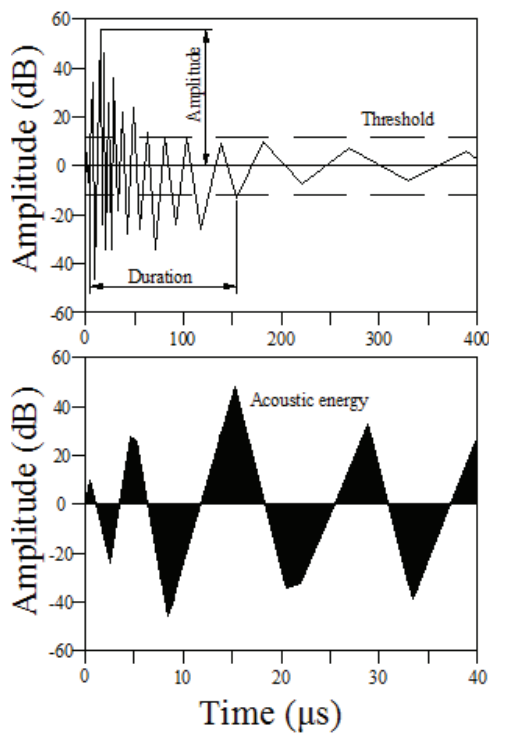

Figure 2. Illustration of a typical waveform and the parameters in AE (Kim \& Weiss, 2003; Malhotra \& Carino, 2004).
Meanwhile, by using one ultrasonic sensor to send a wave and one to record the receipt of the wave, $A E$ could be used actively in ultrasonic wave transmission mode. In this study, the sensor at one end of the sample sent a single pulse, and the sensor at the other end of the sample received it. The travel time of a single pulse transmitting through the sample could be obtained, which could be used to estimate the elastic modulus and the extent of damage (Li et al., 2011).

\section{EXPERIMENTAL}

\subsection{Materials}

The mortar in this study is a typical ordinary portland cement mortar with water cement ratio $(\mathrm{w} / \mathrm{c})$ of 0.42 . No air-entraining agent was added. Deionized water was used during casting. The mixture proportions of the mortar are shown in Table 1. Ten samples were cast with the dimension of $25 \mathrm{~mm} \times 25 \mathrm{~mm} \times 125 \mathrm{~mm}$. After 1 days of curing, the prisms were demolded and sealed in double plastic bags at a temperature of $23 \pm 0.5^{\circ} \mathrm{C}$ for 43 days.

Table 1. Mixture proportion of mortar used in this study.

\begin{tabular}{lc}
\hline Material & Mass $\left(\mathbf{k g} / \mathbf{m}^{3}\right)$ \\
\hline Cement & 611.6 \\
Water & 282.4 \\
Fine aggregate & 1418.4 \\
\hline
\end{tabular}

After curing, the mortar prisms were put in a vacuum oven at a temperature of $75 \pm 1^{\circ} \mathrm{C}$ for 3 days with a vacuum pressure of $30 " \mathrm{Hg}(10 \mathrm{kPa})$. When drying was complete, vacuum saturation technique was used to conditioning specimens to $100 \%$ degree of saturation. These mortar prisms were put in a vacuum tank to a residual pressure of $10 \mathrm{mmHg}(1,333 \mathrm{~Pa})$ for $3 \mathrm{~h}$, while still under vacuum, salt solutions were introduced into the vacuum tank covering the prisms. Table 2 shows the concentrations of $\mathrm{NaCl}$ solutions used to saturate the mortar samples. According to phase diagram of $\mathrm{NaCl}$ solution, a small concentration $(0.7 \%)$, two intermediate concentrations ( 3 and $10 \%$ ), and the eutectic concentration (23.3\%) were chosen.

Table 2. Salt solution concentrations used in this study.

\begin{tabular}{cccccc}
\hline Salt solution & & \multicolumn{5}{c}{ Concentration (\%) } \\
\hline $\mathrm{NaCl}$ solution & $\begin{array}{c}0 \text { (deionized } \\
\text { water) }\end{array}$ & 0.7 & 3 & 10 & 23.3 \\
\hline
\end{tabular}

One hour after introducing the salt solutions, the container with salt solution covering samples were removed from the vacuum tank, and maintained at a temperature of $23 \pm 0.5^{\circ} \mathrm{C}$ for another 2 days. This condition was considered as saturated (i.e., 100\% degree of saturation). 


\subsection{Sample preparation for $A E$ testing with freeze-thaw cycles}

After the samples were conditioned to complete saturation (i.e., a $100 \%$ degree of saturation), the mortar samples were first wrapped with a thin plastic sheet and then covered by a paper towel wetted by the corresponding salt solution as shown in Figure 3(a) and (b), respectively. The mortar samples were then sealed lightly with a "heat shrink wrap" to further prevent them from absorbing or releasing solutions during freeze-thaw cycles as shown in Figure 3(c). The "heat shrink wrap" loosely wrapped the middle of the sample to allow shrinkage and expansion of the sample, but shrunk at two ends using a heat gun, the same procedure described in ASTM C666-03 (2008).

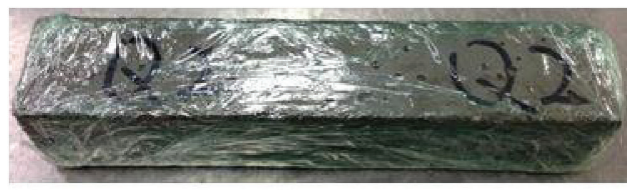

(a)

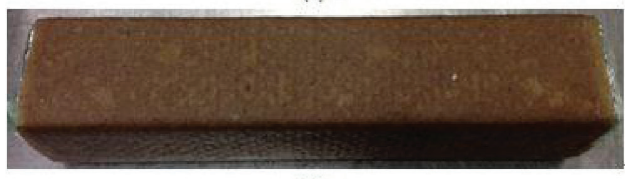

(b)

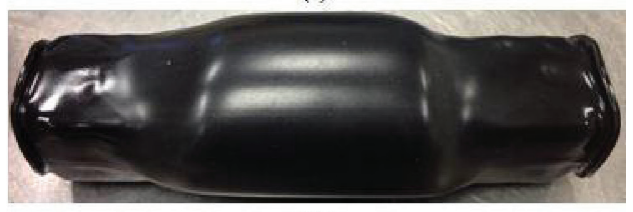

(c)

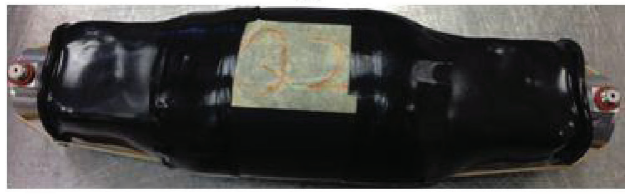

(d)

Figure 3. Mortar sample preparation for AE testing with freezethaw cycles: (a) thin plastic sheet wrapping the sample; (b) wet paper towel; (c) heat shrinkage wrap; (d) two AE sensors attached at the two ends of the samples.

The AE sensors were attached at two ends of the sample by high vacuum grease as a coupling agent. To keep the sensors in good contact with the samples, rubber bands were used to attach the sensors to samples by supplying a light mechanical force, as shown in Figure 4(d). After preparation, samples were put in the freeze thaw chamber to start freeze-thaw cycles. To eliminate vibration and noise from the chamber and surroundings, samples were put in a plate hung from the chamber.

\subsection{Temperature cycle for freeze-thaw experiments}

Figure 4 shows the temperature cycle of the freeze thaw chamber, the surface and center of mortar samples. The temperature was decreased from 10 to $-18^{\circ} \mathrm{C}$ in $2 \mathrm{~h}$, maintained at $-18^{\circ} \mathrm{C}$ for $17 \mathrm{~h}$, increased to $10^{\circ} \mathrm{C}$ in $2 \mathrm{~h}$, and maintained at $10^{\circ} \mathrm{C}$ for $3 \mathrm{~h}$.

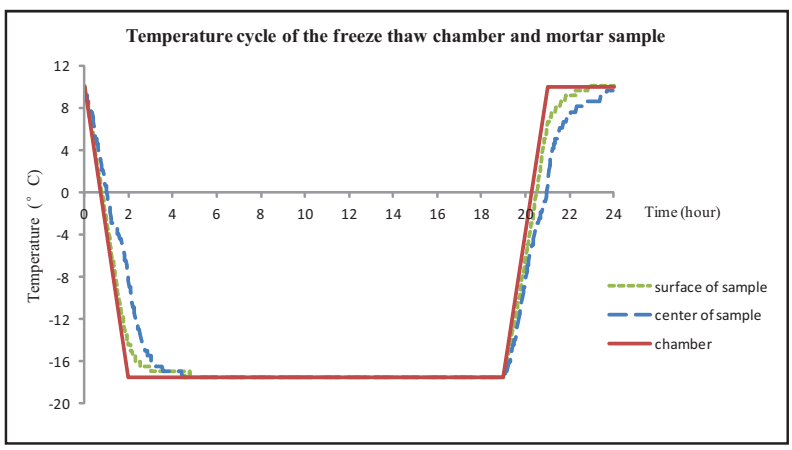

Figure 4. Temperature cycles of the freeze thaw chamber and mortar sample.

\section{RESULTS AND DISCUSSION}

\subsection{Freezing temperature}

Many acoustic events were detected and recorded by two sensors attached at the two ends of samples during freeze-thaw cycles. Figure 5(a) shows the amplitude of acoustic events recorded by an acoustic sensor for mortar sample saturated with $10 \% \mathrm{NaCl}$ solution during the first freeze-thaw cycle, together with the temperature cycle of the surface of the mortar sample. Each symbol on the plot corresponds to an acoustic event. Most of the acoustic events happened slightly after the temperature of the sample crossed the liquidus line. It was observed that of the crossing of the liquidus line resulted in a substantial number of acoustic events. Therefore, the onset of the large number of acoustic events can be related to the average freezing temperature of solution in mortar.

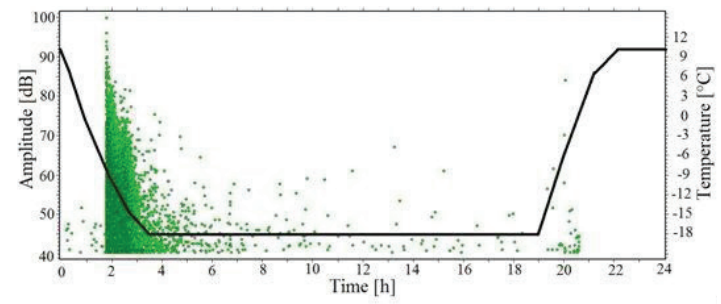

(a)

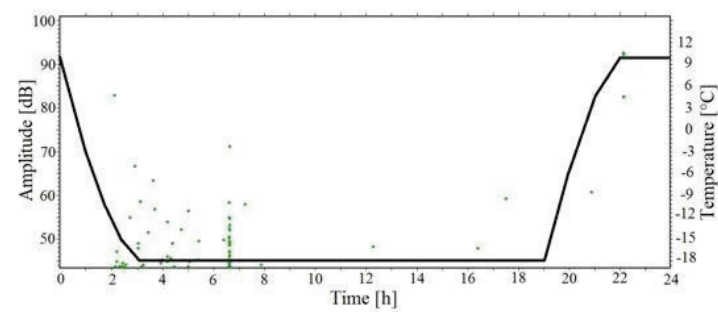

(b)

Figure 5. Acoustic events recorded for sample saturated with (a) $\mathrm{NaCl} 10 \%$ and (b) $\mathrm{NaCl} 23.3 \%$ during the first freeze-thaw cycle. 
Table 3 lists the average freezing temperature corresponding with the increase in $\mathrm{AE}$ events for mortar samples saturated with $\mathrm{NaCl}$ solutions of various concentrations. For deionized water, 0.7, 3, and $10 \% \mathrm{NaCl}$ solutions, the large number of acoustic events occurred at the temperature that was lower than liquidus line, and much lower than $0^{\circ} \mathrm{C}$. Fagerlund (1973a, 1973b) and Helmuth (1960) attributed this phenomenon to pore confinement and dissolved ions in solutions. Through low temperature calorimetry studies, Sellevold and Farstad (1991) showed that the freezing point of bulk water was depressed by the presence of dissolved ions. Many studies (Fagerlund, 1973a, 1973b; Ribeiro et al., 2006; Strub et al., 2003) have shown that once ice crystallization starts, the ice crystal grows and propagates very fast. Helmuth (1960) even stated the propagation rate of the ice front of about $10 \mathrm{~mm} / \mathrm{s}$. It could be reasoned that in this study that when the ice in the $\mathrm{NaCl}$ solution formed it would grow quickly resulting in cracking and acoustic activity. The temperature at the surface of the mortar is lower than the center of the mortar. The AE starting temperature is regarded as the freezing temperature of salt solution in mortar. For deionized water, 0.7, 3 , and $10 \% \mathrm{NaCl}$ solutions in mortar, the freezing temperature decreases with increasing concentration. It should be noted however that the rapid decrease in temperature results in some uncertainty in this measurement. Additional testing is currently underway with slower freezing rates to obtain more precise freezing temperature that enables ice volume calculation over time using the phase diagram.

Table 3. The AE starting temperature and bulk freezing temperature of solutions according to the phase diagram.

\begin{tabular}{|c|c|c|c|}
\hline \multirow{2}{*}{$\begin{array}{c}\text { Cycles } \\
\text { Solutions }\end{array}$} & \multicolumn{2}{|c|}{$\begin{array}{l}\text { Temperature at which the } \\
\text { AE activity started }\left({ }^{\circ} \mathrm{C}\right)\end{array}$} & \multirow{2}{*}{$\begin{array}{c}\text { Liquidus } \\
\text { temperature of } \\
\text { salt solution }\left({ }^{\circ} \mathrm{C}\right)\end{array}$} \\
\hline & $\begin{array}{c}\text { Surface of } \\
\text { mortar }\end{array}$ & $\begin{array}{c}\text { Center of } \\
\text { mortar }\end{array}$ & \\
\hline $\begin{array}{l}\text { Deionized } \\
\text { water }\end{array}$ & -9.79 & -3.53 & 0 \\
\hline $\mathrm{NaCl} 0.7 \%$ & -10.24 & -3.71 & -0.35 \\
\hline $\mathrm{NaCl} 3 \%$ & -13.20 & -5.38 & -1.64 \\
\hline $\mathrm{NaCl} 10 \%$ & -15.71 & -11.19 & -6.56 \\
\hline $\mathrm{NaCl} 23.3 \%$ & $\mathrm{~N} / \mathrm{A}$ & $\mathrm{N} / \mathrm{A}$ & -21 \\
\hline
\end{tabular}

Note: N/A represents "not available".

The temperature at which the AE activity began for the $23.3 \% \mathrm{NaCl}$ solution are not listed because few acoustic events occurred and it is surmised that freezing did not occur (Figure 5 (b)). According to the phase diagram, the liquidus temperature of $23.3 \%$ of $\mathrm{NaCl}$ solution is $-21^{\circ} \mathrm{C}$. In this study, since the lowest temperature of the cycle was $-18^{\circ} \mathrm{C}$, the solutions in the mortar samples are not expected to freeze. In conclusion, in this study, deionized water, $0.7,3$, and $10 \% \mathrm{NaCl}$ solution froze during freezethaw cycles, while $23.3 \% \mathrm{NaCl}$ solution did not.

\subsection{AE energy}

The AE energy is the absolute value of the integral of the voltage versus time. The study by Landis and Baillon (2002) has shown that the AE energy might be proportional to fracture energy for mortar samples under three point bending test. Many studies (Chariton et al., 2002; Hossain et al., 2003; Kim \& Weiss, 2003; PourGhaz \& Weiss, 2010; Puri \& Weiss, 2006; Yang et al., 2005) have used the AE energy to evaluate the extent of damage of concrete materials. In this study, the cumulative acoustic energy was used to quantify the damage of samples saturated with various concentrations of $\mathrm{NaCl}$ solutions. For each concentration, the acoustic energy of four sensors of two samples were calculated and averaged. Table 4 lists the cumulative acoustic energy of mortar samples saturated with various concentrations under freeze-thaw cycles.

Table 4. Cumulative acoustic energy under freeze-thaw cycles (unit: $\mu \mathrm{Vs}$ ).

\begin{tabular}{ccccc}
\hline Solutions & \multicolumn{4}{c}{ Cycles } \\
\cline { 2 - 5 } & $\mathbf{0}$ & $\mathbf{1}$ & $\mathbf{2}$ & $\mathbf{3}$ \\
\hline Dry & 0 & 4.2 & 4.4 & 4.4 \\
Deionized water & 0 & 52.6 & 72.1 & 80.6 \\
$\mathrm{NaCl} 0.7 \%$ & 0 & 78.7 & 124 & 150 \\
$\mathrm{NaCl} 3 \%$ & 0 & 182 & 377 & 554 \\
$\mathrm{NaCl} \mathrm{10 \%}$ & 0 & 469 & 667 & 744 \\
$\mathrm{NaCl} 23.3 \%$ & 0 & 7.0 & 7.7 & 9.4 \\
\hline
\end{tabular}

From Table 4 it can be seen that the cumulative acoustic energy increases with an increasing number of freezethaw cycles. Dry samples had the least acoustic energy, showing the least damage under freeze-thaw cycles. The AE energy and events could be caused by localized stress when aggregates and cement paste have dissimilar volume changes during temperature change (Pour-Ghaz \& Weiss, 2010). For samples saturated with solutions, from deionized water to $10 \% \mathrm{NaCl}$ solution, with increasing concentration, the cumulative acoustic energy increases. While, the acoustic energy of mortar samples with $23.3 \% \mathrm{NaCl}$ solution was close to that of dry samples showing almost no freeze-thaw damage.

\subsection{Calculating damage parameter using active AE}

The relative dynamic elastic modulus is frequently used as an index to evaluate the extent of damage (Li et al., 2011; Litvan, 1988; Litvan \& Sereda, 1980; Shimada et al., 1991). For each mortar sample, two sensors were attached to the two ends and fastened by rubber bands. Before and after each freeze-thaw cycle, when the temperature has been $10^{\circ} \mathrm{C}$ for around $1 \mathrm{~h}$, the pulsing was started. A single pulse was sent by one sensor and received by the other sensor of the sample. The transmission time and velocity of the pulse could be measured and calculated in both directions (from sensor 1 to 2 and from sensor 2 to 1 ). 
Each sensor sent four pulses. The mean value of velocities of eight pulses after each freeze-thaw cycle was calculated. The relative elastic modulus, i.e. $E_{t} / E_{0}$, is square proportional to the relative velocity of wave transmitting through materials (ASTM C666-03, 2008; Li et al., 2011), as shown in Equation (2). The damage parameter (D) can also be estimated.

$$
D=1-\frac{E_{\mathrm{t}}}{E_{0}}=1-\left(\frac{V_{\mathrm{t}}}{V_{0}}\right)^{2}
$$

where $E_{0}, V_{0}$ represent elastic modulus and corresponding velocity of wave transmission before freeze-thaw cycle, respectively; and $E_{t}, V_{t}$ represent elastic modulus and corresponding velocity of wave transmission after various freeze-thaw cycles, respectively (Pour-Ghaz \& Weiss, 2010).

From Table 5, it can be seen that the damage parameter increases with increasing freeze-thaw cycles. Corresponding to the cumulative acoustic energy, dry samples showed the smallest damage parameter. The damage parameter of samples saturated with deionized water was $55.4 \%$ after three freeze-thaw cycles, showing samples was severely damaged, while the damage parameter of dry samples was only $2.2 \%$. Samples saturated with 0.7 and $3 \% \mathrm{NaCl}$ solutions had damage parameters that were similar to those of samples saturated with deionized water. Samples saturated with $10 \% \mathrm{NaCl}$ solution had much higher damage parameter than deionized water, $40 \%$ after one freeze-thaw cycle and $86.9 \%$ after three freeze-thaw cycles, while for $23.3 \% \mathrm{NaCl}$ solution, the damage parameter was much less than $10 \%$ of brine solution, and less than deionized water.

Table 5. Damage parameter under freeze-thaw cycles.

\begin{tabular}{ccccc}
\hline Solutions & \multicolumn{4}{c}{ Cycles } \\
\cline { 2 - 5 } & $\mathbf{0}$ & $\mathbf{1}$ & $\mathbf{2}$ & $\mathbf{3}$ \\
\hline Dry & 0.0 & 1.9 & 1.9 & 2.2 \\
Deionized water & 0.0 & 16.2 & 38.2 & 55.4 \\
$\mathrm{NaCl} 0.7 \%$ & 0.0 & 23.3 & 39.6 & $\mathrm{~N} / \mathrm{A}^{*}$ \\
$\mathrm{NaCl} 3 \%$ & 0.0 & 22.8 & 33.8 & 43.9 \\
$\mathrm{NaCl} 10 \%$ & 0.0 & 40.1 & $\mathrm{~N} / \mathrm{A}$ & 86.9 \\
$\mathrm{NaCl} 23.3 \%$ & 0.0 & 0.2 & 10.7 & 33.4 \\
\hline
\end{tabular}

Note: N/A represents "not available".

Two values in Table 5 are not available because of the loss of contact between sensors and samples, which resulted in the sensor not being able to capture the signal sent by the other sensor. The possible reason why the damage parameter for $23.3 \% \mathrm{NaCl}$ after three freeze-thaw cycles was a little high is because the vacuum grease applied between the sensors and samples changed properties under low temperature or reacted with $\mathrm{NaCl}$ solution.

\section{CONCLUSIONS}

Based on the experimental results in this study, the following conclusions could be drawn:

1. For deionized water, $0.7,3$, and $10 \% \mathrm{NaCl}$ solutions in mortar samples, the freezing temperature decreases with increasing concentration due to pore confinement and existence of dissolved ions. A large number of $A E$ events are recorded when the solution begin to freeze. The cumulative $\mathrm{AE}$ energy and damage parameter of mortar samples increase as the number of freeze-thaw cycles increases. With increasing concentration, the acoustic energy and damage parameter increased showing severe freeze-thaw damage.

2. The mortar sample containing a solution with a concentration at the eutectic composition $(23.3 \%$ $\mathrm{NaCl}$ ) does not freeze during freeze-thaw cycles with the minimum temperature of $-18^{\circ} \mathrm{C}$. Although the degree of saturation of mortar is $100 \%$, the acoustic energy and damage parameter of samples saturated with $23.3 \% \mathrm{NaCl}$ solutions are close to dry samples showing almost no freeze-thaw damage, and much smaller than those of other solutions which freeze during freeze-thaw cycles.

\section{ACKNOWLEDGMENT}

The experiments reported in this article were conducted in Pankow Materials Laboratory at Purdue University. The authors are grateful for support from the Joint Transportation Research Program administered by the Indiana Department of Transportation and Purdue University. The contents of this article reflect the views of the authors, who are responsible for the facts and the accuracy of the data presented herein, and neither do necessarily reflect the official views or policies of the Indiana Department of Transportation, nor do the contents constitute a standard, specification, or regulation.

\section{REFERENCES}

ASTM International. (2008). Standard test method for resistance of concrente to rapid freezing and thawing (C666/C666M-03). West Conshohocken, PA: ASTM International.

Bentz, D. P., Ehlen, M. A., Ferraris, C. F., \& Garboczi, E. J. (2001). Proceedings of the 7th International Conference on Concrete Pavements, Vol. 1. International Society for Concrete Pavements. September 9-13, 2001, Orlando, FL, 181-193.

Charlton, T., Kim, B., \& Weiss, W. J. (2002). Using passive acoustic energy to quantify cracking in volumetrically restrained cementitious systems. 15th ASCE EMD Conference, American Society of Civil EngineersEngineering Mechanics Division, New York, NY. 
Fagerlund, G. (1973a). Critical degrees of saturation at freezing of porous and brittle materials (Dissertation). Lund Institute of Technology, Division of Building Technology, $500 \mathrm{p}$.

Fagerlund, G. (1973b). Determination of poresize distribution from freezing-point depression. Materials and Structures, 6(3), 215-225.

Fagerlund, G. (1975). The significance of critical degrees of saturation at freezing of porous and brittle materials. Durability of Concrete, American Concrete Institute, 13-65.

Fagerlund, G. (1977a). The critical degree of saturation method of assessing the freeze/thaw resistance of concrete. Materials and Structures, 10(4), 217-229.

Fagerlund, G. (1977b). The international cooperative test of the critical degree of saturation method of assessing the freeze/thaw resistance of concrete. Materials and Structures, 10(4), 231-253.

Fagerlund, G. (1981). The principles of frost resistance of concrete. Nordisk Betong, 2, 5-13.

Grant, S. A. (2000). Physical and chemical factors affecting contaminant hydrology in cold environments. DTIC Document. Technical Report: ERDC/CRREL TR-00-21. US Army Corps of Engineering, Cold Research \& Engineering Laboratory, $27 \mathrm{p}$.

Helmuth, R. (1960). The capillary size restrictions on ice formation in hardened portland cement pastes. Report \#: No 156. Skokie, IL : Portland Cement Association, Research and Development Laboratories.

Hossain, A. B., Pease, B., \& Weiss, J. (2003). Quantifying early-age stress development and cracking in low water-to-cement concrete: Restrained-ring test with acoustic emission. Transportation Research Record: Journal of the Transportation Research Board, 1834(1), 24-32.

Ketcham, S. A., Minsk, L. D., Blackburn, R. R., \& Fleege, E. J. (1995). Manual of practice for an effective anti-icing program. Report No FHWARD-95-202, Federal Highway Administration, US.

Kim, B., \& Weiss, W. J. (2003). Using acoustic emission to quantify damage in restrained fiberreinforced cement mortars. Cement and Concrete Research, 33(2), 207-214.

Landis, E. N., \& Baillon, L. (2002). Experiments to relate acoustic emission energy to fracture energy of concrete. Journal of Engineering Mechanics, 128(6), 698-702.

Li, W., Pour-Ghaz, M., et al. (2011). Water absorption and critical degree of saturation as it relates to freeze-thaw damage in concrete pavement joints. Journal of Materials in Civil Engineering, 24(3), 327.

Litvan, G., \& Sereda, P. (1980). Freeze-thaw durability of porous building materials. Durability of building materials and components. ASTM STP, 691(6), 455-463.

Litvan, G. G. (1988). The Mechanism of Frost Action in Concrete: Theory and Practical Implications. National Research Council, Canada: Institute for Research in Construction.

Malhotra, V. M., \& Carino, N. J. (2004). Handbook on Nondestructive Testing of Concrete. West Conshohocken, PA: ASTM International.

Pour-Ghaz, M., \& Weiss, J. (2010). Quantifying damage due to aggregate expansion in cement matrix. Advances in the Material Science of Concrete, ACI SP-270-9, 101-113.

Powers, T. C. (1945). A working hypothesis for further studies of frost resistance of concrete (pp. 245-272). Washington, DC: American Concrete Institute, Portland Cement Association.

Powers, T. C., \& Helmuth, R. (1953). Theory of volume changes in hardened portland-cement paste during freezing 32, Proceedings of the Thirty-Second Annual Meeting of the Highway Research Board, January 13-16, 1953. Washington, DC: Highway Research Board.

Puri, S., Weiss, J. (2006). Assessment of localized damage in concrete under compression using acoustic emission. Journal of Materials in Civil Engineering, 18(3), 325-333.

Ribeiro, J.-P., Strub, M., Bedecarrats, J.-P., Strub, F., \& Dumas, J.-P. (2006). Thermal and dynamic study of water crystallization at the supercooling breakdown. Journal of Electron Devices, 4, 97-100.

Scherer, G. W. (1999). Crystallization in pores. Cement and Concrete Research, 29(8), 1347-1358.

Scherer, G. W., \& Valenza, J. J. II. (2005). Mechanisms of frost damage. In J. Skalny \& F. Young (Eds.), Materials Science of Concrete VII (pp. 209-246). American Ceramic Society.

Sellevold, E. J., \& Farstad, T. (1991). Frost/salttesting of concrete: Effect of test parameters and concrete moisture history. Nordic Concrete Research, 10, 121-138.

Shimada, H., Sakai, K., \& Litvan, G. G. (1991). Acoustic emissions of mortar subjected to freezing and thawing. Durability of Concrete: Second International Confereence, American Concrete Institute, Detroit.

Strub, M., Jabbour, O., Strub, F., \& Bédécarrats, J. P. (2003). Experimental study and modelling of the crystallization of a water droplet. International Journal of Refrigeration, 26(1), 59-68.

Yang, Z., Weiss, W. J., and Olek, J. (2005). Using acoustic emission for the detection of damage caused by tensile loading and its impact on the freeze-thaw resistance of concrete. Paper presented at ConMat ' 05 - Construction Materials 2005 - Performance, Innovations and Structural Implications, Vancouver, BC, Canada, August 2224, 2005, pp. 1-8. 